Article

\title{
BIM-based Hazard Recognition and Evaluation Methodology for Automating Construction Site Risk Assessment
}

\author{
Inhan Kim ${ }^{1}$, Yongha Lee ${ }^{1}$ and Jungsik Choi ${ }^{2, *(\mathbb{D})}$ \\ 1 Department of Architecture, Kyung Hee University, Yongin-si 17104, Korea; ihkim@khu.ac.kr (I.K.); \\ stays1006@gmail.com (Y.L.) \\ 2 Major in Architecture IT Convergence Engineering, Division of Smart Convergence Engineering, \\ Hanyang University, Ansan-si 15588, Korea \\ * Correspondence: jungsikchoi@hanyang.ac.kr; Tel.: +82-31-400-5962
}

Received: 28 February 2020; Accepted: 27 March 2020; Published: 29 March 2020

\begin{abstract}
Construction sites in Korea are the locus of many disasters and work-related illnesses, and construction workers are particularly likely to be exposed to serious disasters such as falls, collapses, and burial. At domestic construction sites, the concept of Design for Safety has been adopted from abroad, and current regulations are intended to secure the personnel safety at each site. However, current government guidelines and regulations are difficult to apply in the field, mainly because they do not clearly address work issues and safety management measures. The current safety review method depends too much on the subjective experience of site workers or managers. This study analyzes the step-by-step tasks required for more automated building information modeling (BIM)-based construction site safety management. An example BIM-based assessment of one specific construction site hazard, the risk of a worker fall, is carried out. In the risk analysis stage, all of the associated hazards are identified and the attendant risks are estimated and quantified. A broader risk rating methodology is derived based on the scenarios of each possible disaster at a construction site, and the hazards are extracted by defining the relationships between each building element based on the BIM information. The result is a risk rating methodology derived from a BIM-based risk assessment.
\end{abstract}

Keywords: building information modeling (BIM); hazard recognition; risk assessment; safety management

\section{Introduction}

Accidents in the Korean construction industry have been increasing in recent years, with deaths in the construction industry now accounting for nearly half of all workplace deaths in the entire industrial sector (344 out of 730 total industrial deaths) [1]. This means that the severity of disasters that occur at construction sites is higher than at other industrial sites. Construction workers are primarily exposed to falls, slipping, getting hit by objects, and getting cut. Of these, falls are most prevalent, accounting for 8608 out of 24,718 total construction accidents [2]. Current research on safety management at domestic construction sites is based on analysis of construction site incident data, the establishment of safety management plans, fostering employee safety awareness, and assessment of disaster factors. From these, new directions or methodologies of future safety management are suggested. Specific risk assessments for potential construction disasters are mainly based on the experience and supervision of construction site managers.

Overseas, in order to manage safety in the workplace, the concept of a Sustainable Construction Safety and Health (SCSH) rating system, Prevention through Design (PtD), Construction Safety Audit 
Scoring System (ConSASS), etc. were established by the government agencies such as Occupational Safety and Health Administration (OSHA) in the United States, Health and Safety Executive (HSE) in the UK, and Building and Construction Authority (BCA) in Singapore. Evaluation methods and processes have long been established for practical application. Guidance and relevant laws and regulations are also in place and are distributed in consideration of practical application; some countries require safety evaluation results at the early stage of design licensing. In addition, a number of studies are being conducted to apply Building Information Modeling (BIM) technology and methodology to the safety management of construction sites [3-5].

Workers at construction sites are exposed to a number of hazards which, if eliminated, should reduce the risks of the entire workplace to ensure worker safety [6]. The Korean government is trying to improve risk management at construction sites. It has established the concept of Design for Safety and is distributing design safety checklists and work manuals, and has enacted regulations to ensure construction site safety from the early design stage. Although research on this is being actively conducted, accurate and quick review is difficult due to the large amount of information required for direct application in the field and the absence of a consistent review plan methodology.

\section{Literature Review}

In Korea and other countries, many efforts have been made to manage construction worksite safety by proposing various policies along with the dissemination of guidelines from relevant government agencies.

\subsection{Status of Safety Management}

Figure 1 shows the overall process of safety management [7]. Safety management determines the weight of various risks (risk estimation) in the workplace and directs mitigation measures based on their acceptability (risk assessment). In other words, the process of minimizing workplace risks to an acceptable level is to repeat as often as necessary the risk estimation followed by hazard reduction. The resulting safety modifications should be documented and the results of the safety management efforts should be verified by submitting them to the relevant nationally recognized agencies or government agencies. Several guidelines and policies are available to support or automate this process.

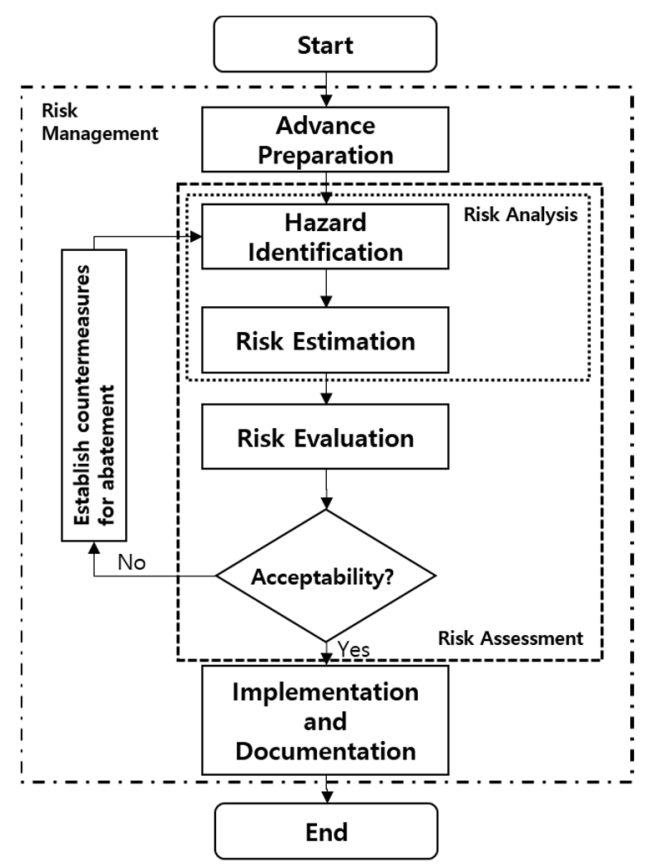

Figure 1. Safety Management Process. 


\subsubsection{Risk Analysis}

Hazard identification is the process of identifying hazards that may pose risks in the workplace. Hazards are identified according to variables such as each member, material, and work type, with the goal of recognizing and eliminating the exposed and potential risks in the workplace. For this purpose, safety supervisors are dispatched to determine the hazards at each workplace, which are then used to quantify the risk of disasters [8].

Risk estimation is the process of estimating the extent of each hazard and the potential extent of damage based on those hazards, and estimating the associated degree of risk. Quantitative figures for each element are provided to provide information on the degree of risk for the hazards. To determine the degree of risk, the severity and frequency of the hazards should be determined by a qualified expert. However, the resulting values may vary depending on the expert's experience and subjectivity in this process [4].

\subsubsection{Risk Assessment}

The risk assessment evaluates the acceptability of the risk rating based on the hazards in the workplace extracted at the hazard identification stage. The risk rating (materiality and frequency) of each hazard is considered a measure of safety management according to the estimation results, so the workplace risk is indicated through a quantitative numerical value. Risk is expressed as a risk rating, and the risk rating is calculated according to Equation (1) in Section 4.1. Specifically, the risk rating is expressed by multiplying each item based on its severity and frequency of occurrence. Efficient safety management can be achieved by judging acceptability based on these quantitative figures or by applying additional risk reduction measures at the discretion of the manager, to reduce the workplace risk to an acceptable level [9].

The current domestic risk assessment is expressed as the coefficient of the severity and frequency of occurrence disasters. This measures each coefficient in a different way than quantitative numerically based risk assessment models such as business risk assessment [10]. However, in the case of workplace risk assessment, the frequency and severity coefficient is calculated based on the accident cases occurring in the past or present. Table 1 shows the calculation criteria for each coefficient. In other words, calculations based on normalized coefficients based on observations and cases are the main ones. However, the definition, calculation method, and calculation criteria for each coefficient vary depending on experts or organizations.

Table 1. Criteria for risk rating estimation.

\begin{tabular}{|c|c|c|c|c|c|}
\hline Name & Grade & Contents & Name & Grade & Contents \\
\hline \multirow{5}{*}{ Severity } & 1 & $\begin{array}{l}\text { Death, long-term disability } \\
\text { injuries, or collapse of objects (or } \\
\text { adjacent structures) during } \\
\text { construction }\end{array}$ & \multirow{5}{*}{ Frequency } & 1 & $\begin{array}{l}\text { If there is a record of occurrence } \\
\text { of accidents in the last } 3 \text { months } \\
\text { or there is a possibility that it } \\
\text { may occur about once a month }\end{array}$ \\
\hline & 2 & $\begin{array}{l}\text { Loss of construction period of } \\
\text { more than one week due to } \\
\text { injury or serious damage to the } \\
\text { object (or adjacent structures) } \\
\text { causing a disaster. }\end{array}$ & & 2 & $\begin{array}{l}\text { If there has been a record of } \\
\text { accidents occurring in the past } \\
\text { year or about once a year }\end{array}$ \\
\hline & 3 & $\begin{array}{l}\text { In the case of non-business } \\
\text { disasters including minor } \\
\text { disasters, or due to slight } \\
\text { damage to the target (or adjacent } \\
\text { structures), loss of construction } \\
\text { period within } 3 \text { days }\end{array}$ & & 3 & $\begin{array}{l}\text { If there has been a record of } \\
\text { accidents in the last } 5 \text { years, or } \\
\text { there is a possibility of } \\
\text { occurrence once every } 3 \text { years }\end{array}$ \\
\hline & 4 & $\begin{array}{l}\text { No damage during construction } \\
\text { due to no injury }\end{array}$ & & 4 & $\begin{array}{l}\text { If there has been a record of } \\
\text { accidents in the last } 10 \text { years or } \\
\text { there is a possibility that it may } \\
\text { occur once every } 5 \text { years }\end{array}$ \\
\hline & & & & 5 & $\begin{array}{l}\text { There is no record of accident } \\
\text { occurrence in } 10 \text { years }\end{array}$ \\
\hline
\end{tabular}


There is no clear standard for risk assessment in Korea, as risk assessment following the establishment of mitigation measures also depends on expert supervision or experience. The same is true in foreign countries, and in order to minimize this, various guidelines for construction site risk assessment and safety management are distributed.

\subsection{Case Study}

This aim of this study is to develop a methodology to automate the risk analysis process. After an extensive literature review on domestic and foreign safety management methodologies, we here propose a BIM-based risk assessment method and an evaluation plan that uses representative disaster assessment examples. In the process of risk assessment, risk recognition and risk estimation methods are established in the BIM model, and the risk estimation is carried out by extracting each hazard and calculating its risk rating.

The concept of risk for risk management is here established through several safety management guidelines, including Design for Safety, ConSASS, and OSHA, and we conducted a survey on the elements required for appropriate safety management in the example construction site and the evaluation cases.

\subsubsection{Korea}

In Korea, construction design safety is based on 2D information such as design drawings and construction drawings in the design or construction stage, from which the hazards that can occur in the construction site can be derived and the countermeasures established for the safety management at the site. However, it is difficult to generalize the evaluation elements because they differ according to each site and site safety manager, and no clear standard definitions exist. Also, the fact that the review is conducted based on 2D information limits the information available to reviewers, making the review process itself dependent on the manager's experience and subjectivity. This compromises the objectivity and consistency of the review results. Finally, although the requirement for design safety reviews was newly established under Article 75(2) of the Enforcement Decree of the Construction Technology Promotion Act, it is not widely applied in the field due to lack of publicity and the ambiguity of the guidelines. In other words, there are institutional and technical limitations to field applications [11,12].

The guidance outlines risk assessment methods based on a $4 \times 5$ matrix. In addition to the existing risk assessment, only the assessment of the reduction measures through consultation with experts in each field on the reduction measures will be conducted separately. In the case of risk assessment, quantitative assessment is conducted according to the coefficient of severity and frequency. However, in the absence of criteria for risk assessment, the evaluation matrix is applied differently depending on the site, such as $4 \times 4$ or $4 \times 5$, etc. Also, due to the absence of items required for a consistent risk assessment, such as the criteria for calculating the risk level and the method for recognizing the hazards, the evaluation is conducted depending on the subjectivity and experience of experts. With the above reasons, it is difficult to evaluate the risk of design for safety review.

\subsubsection{Singapore}

In Singapore, the ConsASS, which combines buildability and safety, is under the purview of the BCA. Buildability is an evaluation index introduced to improve the productivity of designers, being a quantitative evaluation of worker productivity in the design and construction process by characterizations by work type, structure, and object [13]. In addition, the concept of Design for Safety has been introduced to distribute design guidelines for safety from the concept design stage to the pre-construction stage based on the G (Group together) U (Understand) I (Identify) D (Design) E (Enter) (GUIDE) process [14,15]. In addition to this, a risk assessment template is provided to record and submit information on the risk level, reduction measures, and whether to reduce hazards due to design changes. 
Based on ConSASS, a safety score is compiled. Currently, the BIM model is being submitted for safety score review in Singapore's licensing stage, but the significance of the BIM model is fading as the BIM model itself is being reviewed through 2D drawings. In addition, since the review depends on 2D drawings and buildability, additional site information is required for detailed and accurate review of the site hazards [16]. In other words, the qualitative risk assessment and quantitative risk assessment, such as design for safety review, ConSASS, and ConSASS Checklist, are carried out together to implement an integrated risk assessment.

\subsubsection{United Kingdom}

In the UK, the Health and Safety Executive (HSE) supervises the work scope and elements for safety management from the initial design stage to the end stage based on the safety regulations. Under the concept of Construction Design and Management (CDM), checklists of the hazards that occur in the construction site are provided, which facilitate the acquisition of information for managers and workers by classifying the hazards. However, this is difficult to manage objectively and consistently as the result of different checks according to the person in charge of the narrative checklist $[17,18]$. In other words, the subjectivity of the safety manager may be involved in the evaluation due to the absence of objective evaluation indicators, and it is difficult to detect risks in advance because it is not a drawing- or model-based evaluation.

\subsubsection{United States}

Under OSHA in the United States, PtD has been introduced based on cooperation with and between designers and engineering firms to encourage workplace safety. Safety management is based on the SCSH rating system, which is itself based on an independent safety management checklist that takes into account the U.S. construction environment $[19,20]$. In particular, the SCSH rating system is designed to conduct quantitative risk assessment by providing a scoring template for risks that may occur within the project as well as at the construction site. In addition, a preliminary study for the risk assessment of each item of the Design for Construction Safety (DFCS) is also conducted to classify and quantify the design elements for each risk item [21]. Current studies on the automatic recognition of fall hazards and safety management based on BIM are being actively conducted [4,5]. In summary, many elements have been developed in that country for automated risk assessment but the scope of such application is limited, such as hazard recognition for falling disasters and risk item establishment for commercial facilities.

\subsubsection{Hong Kong}

This administrative region distributes guidelines for Design for Safety, checklists, and work instructions for each design stage. Based on examples of relevant project cases and itemized evaluation elements, the guidelines are produced and distributed to increase their practical applicability. Hong Kong also applies certified standards for safety design considering the building life cycle, and a clear list of hazards is provided for each construction project to ensure safety management through objective and consistent risk assessment [22,23]. This is based on the $3 \times 3$ evaluation model, and distributes guidelines that specify the contents of the hazard recognition and evaluation methods required in the risk assessment process so that the risk assessment at the construction site can be consistently performed. Guidelines and laws have been distributed for an objective and consistent risk assessment by mandating the creation of items such as risk assessment results, mitigation measures, and related personnel etc.

\subsection{Related Research Trend}

Several studies have been conducted on the existing risk assessment. Among them, in the case of risk assessment model research, the risk level of the hazards derived based on the general construction project was calculated, and the risk of each project was estimated based on the average risk rating 
value. In addition, research on evaluation items and evaluation methods for consistent risk assessment in domestic construction sites, such as estimating the risks for construction site based on the average of the risk ratings with the design safety review items, is conducted. However, it is difficult to solve the fact that the subjectivity and experience of experts are likely to influence the evaluation process, which is a chronic problem in domestic risk assessment, mainly based on the premise of existing risk assessment methods. [24,25]

In order to compensate for this, in the case of foreign countries, a study was conducted on how to recognize hazards related to a fall disaster based on the BIM model. Based on the BIM model, the fall hazards of each member were recognized, but it was limited to the U.S. environment and did not reach the risk assessment level. In other words, BIM-based research of hazard identification has been conducted, but studies on how to use the recognized hazards are insufficient.

\subsection{Summary}

At present, in the domestic and overseas construction industry, the main method of determining hazards for safety management is to identify them through 2D drawings and expert site inspections. However, due to the lack of clear work instructions and evaluation elements, the reviewer's experience and subjectivity are involved, making it impossible to obtain absolute objectivity and consistent results. For example, if safety management is carried out by different safety managers in the same construction site, their evaluations will be very different and the results will not be reliable. This is also happening because different standards are applied in the same disaster in each country or place. Therefore, the establishment of clear and consistent evaluation criteria is the first step in securing the reliability of safety management. To address this, the methodology in this study clearly defines the hazards of each disaster and its risk rating, and extracts the hazards by reviewing the disaster scenario based on the relationship between the 3D shape information of BIM and each object. The main purpose here is to increase the accuracy and productivity of the risk extraction stage.

\section{Identify Hazards for Disaster Risk Assessment}

In order to derive risks from BIM information, the definition of disasters in the BIM model should be prioritized. We selected the scope of the abstract and extensively evaluated disasters described in the construction site safety management information database administered by the Ministry of Land, Infrastructure and Transport, Construction Safety System; the authors narrowed the evaluation scope by collecting the most-frequently occurring scenarios [26]. Based on the scenarios for each disaster, the researchers derived the evaluation elements; then, in order to conduct a safety review using BIM data, scenarios for each disaster were collected and analyzed to identify the causes, locations, risks, and frequency of disasters occurring in construction sites. The types of disasters (human and material disasters) were categorized by each disaster.

The classified data were assigned risk ratings for 430 possible disaster scenarios in construction sites to calculate the risk level for each disaster, by linking the frequency of occurrence according to the type and severity of the disaster according to its source. Based on the BIM model, we selected five representative disasters to be extracted and evaluated, i.e., fall, collision, stuck, bury and drop (hit by object). According to the scenarios of each of these disasters, the BIM-based hazards were extracted through placement information and shape information between objects.

\subsection{Representative Disaster Scenario Selection}

To evaluate the selected disaster scenarios, we listed the causes in each scenario and then conducted an analysis to derive the hazards. We then selected the fall disaster, which is the most frequently occurring disaster at construction sites, as the ultimate representative disaster, and collected the occurrence scenarios for falls. Considering data on disaster sites, disaster processes, and disaster conditions, we found that the most common construction fall location in Korea is reinforced concrete beams. Among the processes associated with reinforced concrete, the scenario of a worker falling 
during rebar assembly was selected as a representative scenario, and we performed a risk assessment as an example of our BIM-based methodology.

\subsection{BIM-based Hazard Derivation}

For risk assessment based on BIM, we conducted an open BIM-based evaluation based on the standard International Information Format (IFC). As shown in Figure 2, the risk assessment was carried out for the building object (IfcBuildingElement) that is the main source of disasters among BIM objects. Within this object, we defined the beams, columns, and slabs to extract information for "fall accidents issued from reinforcing bars," which was the representative disaster being evaluated in this study. The results from IfcBeam, IfcColumn, and IfcSlab produced the shape information, arrangement information, and work information of the target object. From these, we collected all of the possible disaster scenarios related to reinforcing beam objects.

\begin{tabular}{|l|l|}
\hline IfcProduct & IfcBuildingElement \\
\hline IfcBeam \\
\hline IfcColumn \\
\hline IfcDoor \\
\hline IfcMember \\
\hline IfcWall \\
\hline IfcSlab \\
\hline IfcRamp \\
\hline IfcStair \\
\hline IfcRoof \\
\hline IfcStairFlight \\
\hline IfcRampFlight \\
\hline IfcCurtainWall \\
\hline IfcRailing \\
\hline IfcWindow \\
\hline
\end{tabular}

Figure 2. Structure of IfcBuildingElement.

As shown in Figure 3, in order to derive hazards using the BIM model, we extracted the relationships of the assembly and work information of each object [27]. In addition, through the connection relationships with each object, we could further extract potential disasters such as falls occurring during beam assembly and during pillar-beam-slab assembly.

\subsection{Hazard Extraction}

The hazards of the slab-column-beam object are shown in Figure 3, wherein each hazard type is classified and visualized by connecting it to the relevant object(s). We could thus extract all of the hazards for beams, columns, slabs, beam-columns, and column-slabs, based on the criteria specified in each national safety guideline. For example, regarding the hazard of a falling beam object, an aerial platform secures worker safety at a height of less than $2 \mathrm{~m}$ above the ground, whereas scaffolding is assembled if the height is more than $2 \mathrm{~m}$ [28]. The condition for the occurrence of a fall disaster risk is "height above $2 \mathrm{~m}$ ". In this way, we extracted the hazards from each BIM model and each building element, and developed a risk assessment based on the risk ratings. 


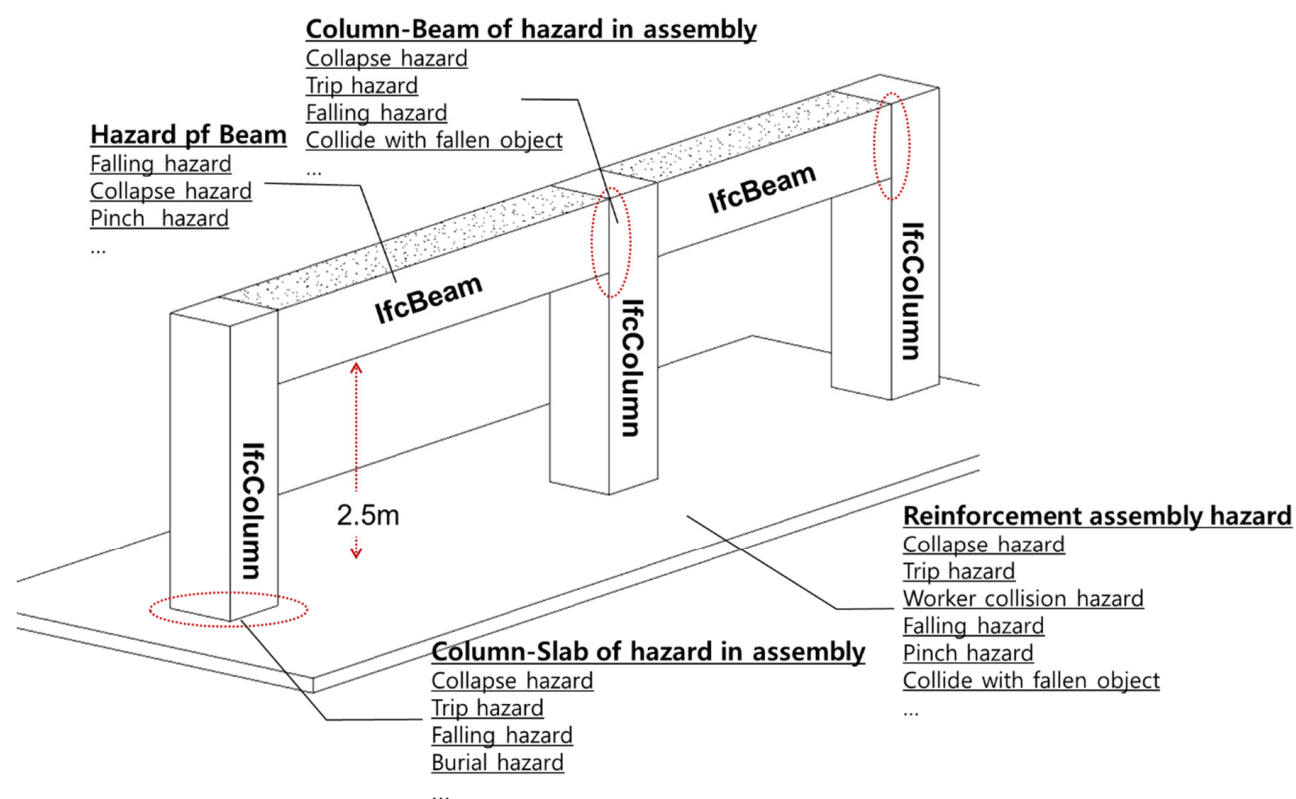

Figure 3. Hazards of IfcBeam-IfcColumn-IfcSlab.

\section{Calculation of BIM-based Risk Rating of Representative Disasters}

In order to calculate the risk rating according to the hazards for each disaster, we selected representative disasters from the past safety accident reports at the construction site, and applied the BIM-based hazards extraction method. As mentioned in Section 3, the risk assessment of fall, collision, stuck, bury and drop (hit by object), which were selected as representative disasters among disasters that may occur at construction sites, will be conducted. This is a list of the most frequently occurring disasters at Korean construction sites. To evaluate the risk rating based on the derived hazards, we conducted the evaluation according to the risk rating calculation method.

\subsection{Risk Assessment Model}

The risk assessment for safety management estimates the risk rating by estimating the frequency and severity of disasters and determines the acceptability of hazards in accordance with the standards of the Korea Occupational Safety and Health Agency (KOSHA). [11] Risk assessments are categorized by frequency levels 1-5 (no possibility $\rightarrow$ frequent) and severity levels 1-4 (no impact $\rightarrow$ severe serious injury). The severity factor is an item that summarizes the effects of disasters on humans according to temporal factors, and the details are shown in Table 1. In addition, the coefficients summarized on the basis of the interval of occurrence of a disaster for each unit period of the disaster are frequency items, and the contents are shown in Table 1.

The risk rating is determined by multiplying the frequency and severity coefficient in Table 1. The formula for estimating risk ratings based on frequency and severity is as follows [29]:

$$
\text { Risk rating }=\text { Severity }(\mathrm{S}) \times \text { Frequency }(\mathrm{F})
$$

The results are summarized in Table 2.

Table 2 shows the values calculated by multiplying occurrence frequency and severity as risk ratings. If the calculated risks are grades 1 to 3 , the risks are negligible, grades 4 to 6 (blue) are insignificant, and grade 8 (green) indicates they can accommodate risk and keep proceeding with work. Risk levels $9 \sim 12$ are a significant risk (orange), and levels 13-15 are a serious risk (also orange), meaning that the scope of the risk work can be accommodated depending on the condition, and work can be resumed if certain safety measures are taken. However, grades 16-20 (yellow) should be discontinued immediately as a "no dangerous work allowed" step. 
Table 2. Risk ratings in Korea.

\begin{tabular}{c|c|c|c|c}
\hline Severity (S) & $\mathbf{1}$ & $\mathbf{2}$ & $\mathbf{3}$ & $\mathbf{4}$ \\
\hline Frequency (F) & 1 & 2 & 3 & 4 \\
\hline 1 & 2 & 4 & 6 & 8 \\
\hline 2 & 3 & 6 & 9 & 12 \\
\hline 3 & 4 & 8 & 12 & 16 \\
\hline 4 & 5 & 10 & 15 & 20 \\
\hline 5 & & &
\end{tabular}

Based on the criteria of Equation (1), risk ratings are calculated based on the hazards for each potential disaster extracted from the BIM model. With the risk rating acceptance levels shown in Table 2, it is possible to calculate which work activities need to have safety measures established. Providing quantitative data on the calculated ratings will enable a quantitative risk assessment based on BIM.

\subsection{BIM-based Risk Extraction}

In order to calculate the risk ratings arising from a fall disaster, the selected representative disaster in this study, the evaluation elements are derived by analyzing the occurrence factors of the fall. According to the KOSHA fall prevention measures, the scenario for a worker's fall accident in aerial work is defined as "If a worker's working height is more than $2 \mathrm{~m}$, a safe aerial work platform must be installed." In other words, if the height of the beam is $2 \mathrm{~m}$ or more, it is judged that there is a danger of the worker falling down when assembling the rebar [28]. Based on such a disaster scenario, the algorithm for risk assessment process is shown in Figure 4.

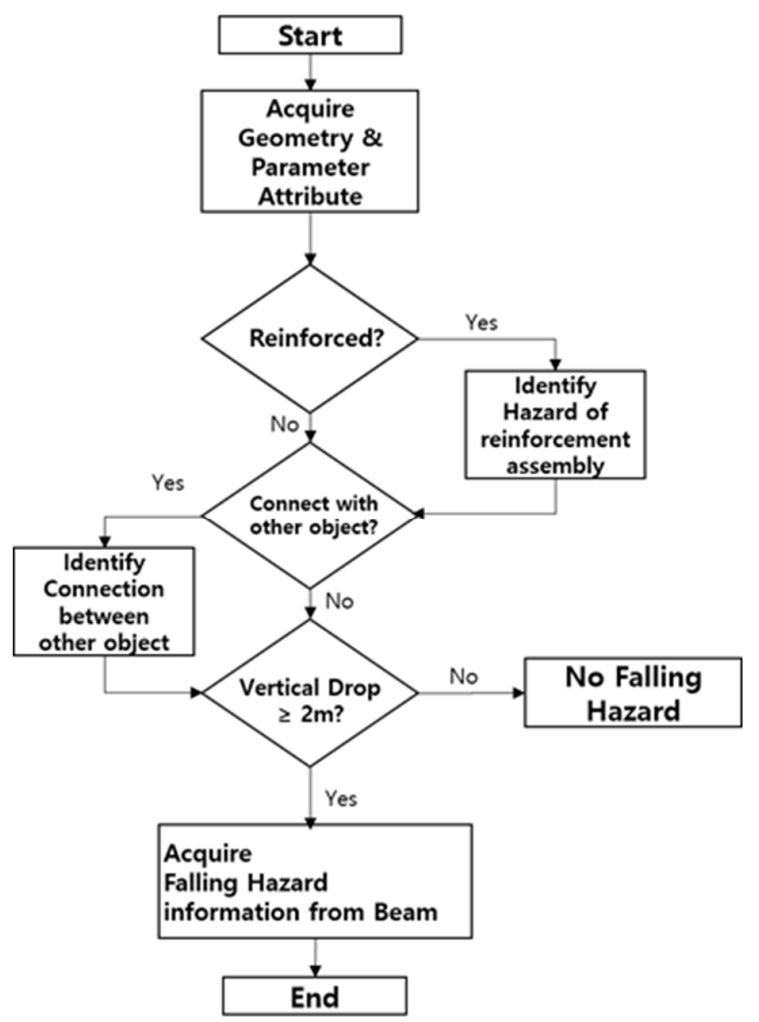

Figure 4. Algorithm of hazard derivation from BIM model. 
Based on the work associated with the beam object, we selected the beam object requiring reinforcing bar assembly and extracted the hazards of the beam object based on its shape and layout information (BIM information). Then, using the criteria in Table 2, decisions can be made as to the allowability of each hazard by combining the calculated risk ratings for each object. Finally, following the steps in Figure 1, the evaluation will determine whether design changes and reassessments are necessary to reduce the risk level to within the allowable range.

\subsection{Risk Assessment for Reapresentative Disaster Scenarios}

Once the BIM-based risks have been extracted, the risk assessment is performed. To do this, the risk assessment elements are extracted based on the given disaster scenario. In the fall scenario under consideration here, the evaluation elements for risk assessment are shown in Table 3.

Table 3. Extraction of fall hazard from disaster scenario.

\begin{tabular}{|c|c|c|}
\hline Disaster Type & Mitigation Measures & Evaluation Item \\
\hline Fall in the workplace & $\begin{array}{l}\text { Installation of a safety aerial work } \\
\text { platform where the working } \\
\text { height is more than } 2 \mathrm{~m}\end{array}$ & $\begin{array}{l}\text { It is dangerous to work at heights over } \\
\qquad 2 \mathrm{~m}\end{array}$ \\
\hline
\end{tabular}

When a worker works at a height of $2 \mathrm{~m}$ or more, the worker is considered to be exposed to a hazard and therefore needs safety measures against a fall disaster. To evaluate this, the height of the beam is interpolated, the beam object that can cause the fall disaster according to its height is selected, and the evaluation is performed. Once the hazards for the selected objects are extracted, the risk rating is calculated according to Equation (1) by estimating the severity and the frequency of the hazards in order to calculate the risk levels for the extracted objects. Table 4 shows the results of calculating the risk class for a fall disaster based on the risk assessment case.

Table 4. Risk assessment result for fall hazard.

\begin{tabular}{ccc}
\hline Hazard & Severity(S) & Frequency(F) \\
\hline $\begin{array}{c}\text { Worker falling during reinforcement assembly } \\
\text { Risk rating }\end{array}$ & 4 & 3 \\
& \multicolumn{2}{c}{ 12(grade) } \\
\hline
\end{tabular}

\subsection{BIM-based Risk Assessment}

Like the risk assessment method for the fall accident associated with reinforcing beams, each hazard of the column-beam-slab shown in Figure 3 is extracted and the BIM-based risk assessment is conducted. Based on the BIM object, the evaluation elements are based on the possible scenarios for each disaster, and the overall risk of the BIM model can be evaluated through the risk assessment. The evaluation elements are the beams, columns, slabs, beam-columns, and column-slabs; accordingly, the risk rating is calculated in Table 5. Each hazard is derived from the work type, layout, and shape information of beams, columns, and slab objects. Then, through the connection relationships, such as beam-column and column-slab, the hazards that could occur in the assembly work between the objects are extracted. A comprehensive risk rating assessment of the extracted items is conducted to comprehensively assess the risk rating of the BIM model. 
Table 5. Results of risk assessment of column, beam and slab.

\begin{tabular}{|c|c|c|c|c|c|c|}
\hline Object & Type & Work Type & Hazard & $\begin{array}{l}\text { Severity } \\
\text { (S) }\end{array}$ & $\begin{array}{l}\text { Frequency } \\
\text { (F) }\end{array}$ & $\begin{array}{c}\text { Risk } \\
\text { Rating }\end{array}$ \\
\hline \multirow{8}{*}{ IfcBeam } & Reinforced Concrete & Assemble reinforcing bar & Fall & 4 & 3 & 12 \\
\hline & Reinforced Concrete & Assemble reinforcing bar & Stuck & 4 & 3 & 12 \\
\hline & Reinforced Concrete & Assemble reinforcing bar & Drop & 3 & 3 & 9 \\
\hline & Reinforced Concrete & Carry reinforcing bar & Drop & 2 & 5 & 10 \\
\hline & Reinforced Concrete & Carry reinforcing bar & Collision & 2 & 5 & 10 \\
\hline & Reinforced Concrete & Formwork & Fall & 4 & 3 & 12 \\
\hline & Reinforced Concrete & Concrete placing & Collision & 3 & 3 & 9 \\
\hline & $\ldots$ & $\ldots$ & $\ldots$ & $\ldots$ & $\ldots$ & $\ldots$ \\
\hline \multirow{8}{*}{ IfcColumn } & Reinforced Concrete & Assemble reinforcing bar & Fall & 4 & 3 & 12 \\
\hline & Reinforced Concrete & Assemble reinforcing bar & Stuck & 3 & 3 & 9 \\
\hline & Reinforced Concrete & Assemble reinforcing bar & Drop & 3 & 3 & 9 \\
\hline & Reinforced Concrete & Carry reinforcing bar & Drop & 2 & 5 & 10 \\
\hline & Reinforced Concrete & Carry reinforcing bar & Collision & 2 & 5 & 10 \\
\hline & Reinforced Concrete & Formwork & Fall & 4 & 3 & 12 \\
\hline & Reinforced Concrete & Concrete placing & Collision & 3 & 3 & 9 \\
\hline & $\ldots$ & $\ldots$ & $\ldots$ & $\ldots$ & $\ldots$ & $\ldots$ \\
\hline \multirow{7}{*}{ IfcSlab } & Reinforced Concrete & Assemble reinforcing bar & Stuck & 2 & 3 & 6 \\
\hline & Reinforced Concrete & Assemble reinforcing bar & Collision & 1 & 5 & 5 \\
\hline & Reinforced Concrete & Carry reinforcing bar & Drop & 2 & 5 & 10 \\
\hline & Reinforced Concrete & Carry reinforcing bar & Collision & 2 & 5 & 10 \\
\hline & Reinforced Concrete & Formwork & Stuck & 3 & 4 & 12 \\
\hline & Reinforced Concrete & Concrete placing & Bury & 3 & 1 & 3 \\
\hline & $\ldots$ & $\ldots$ & $\ldots$ & $\ldots$ & $\ldots$ & $\ldots$ \\
\hline \multirow{5}{*}{ IfcBeam-IfcColumn } & Reinforced Concrete & Assemble reinforcing bar & Fall & 4 & 2 & 8 \\
\hline & Reinforced Concrete & Assemble reinforcing bar & Stuck & 4 & 2 & 8 \\
\hline & Reinforced Concrete & $\begin{array}{l}\text { Reinforcement } \\
\text { placing }\end{array}$ & Stuck & 3 & 3 & 9 \\
\hline & Reinforced Concrete & $\begin{array}{l}\text { Reinforcement } \\
\text { placing }\end{array}$ & Collision & 3 & 3 & 9 \\
\hline & $\ldots$ & $\ldots$ & $\ldots$ & $\ldots$ & $\ldots$ & $\ldots$ \\
\hline \multirow{5}{*}{ IfcColumn-IfcSlab } & Reinforced Concrete & Assemble reinforcing bar & Stuck & 4 & 1 & 4 \\
\hline & Reinforced Concrete & Assemble reinforcing bar & Collision & 2 & 4 & 8 \\
\hline & Reinforced Concrete & $\begin{array}{l}\text { Reinforcement } \\
\text { placing }\end{array}$ & Stuck & 3 & 3 & 9 \\
\hline & Reinforced Concrete & $\begin{array}{l}\text { Reinforcement } \\
\text { placing }\end{array}$ & Collision & 3 & 3 & 9 \\
\hline & $\ldots$ & $\ldots$ & $\ldots$ & $\ldots$ & $\ldots$ & $\ldots$ \\
\hline
\end{tabular}

The hazards for each BIM object were extracted and the risk rating for each hazard was based on the DfS checking task manual [11]. In the case of the fall disaster under consideration here, the 2.5-m-high beam was extracted and the risk rating of the associated fall disaster is 12 , the highest (worst) rating. It should be noted that for any hazard, the frequency and severity of occurrence will vary depending on the site and the work type. In other words, for any given disaster, each risk rating is classified according to the unique location, timing, and process of occurrence.

The assessment presented in this study is an example of a BIM-based risk assessment of one possible construction site disaster, a worker fall. The methodology described here would be difficult to apply to an overall safety management process because only local evaluations are conducted. We will expand and supplement this in the future by adding other disaster scenarios, and the evaluation formula will be supplemented by making evaluations and mathematical models of an entire building. 


\subsection{Simplification for BIM-based Risk Assessment}

In accordance with the risk assessment method above, the risk assessment is conducted through the actual BIM model to represent the final result. By calculating the risk level for each BIM object and removing the duplicated items according to the risk hazard items among the risk evaluation items derived to represent the final result, the risk rating result was derived by showing the risk evaluation results for each process. For the simplification of each hazard, we reviewed the overlapping types of the hazards and the hazards for each object, and derived hazards according to the work by each type. The results of the risk assessment are shown by simplifying the IfcBeam object of Table 5 .

Among them, this study showed the results of BIM-based risk assessment based on the representative disasters presented above. The hazards were derived from the general BIM model and the risk level was calculated to verify the BIM-based risk assessment. First, risk evaluation results are calculated and displayed based on the beam object among BIM model objects, as shown in Table 6.

Table 6. Results of BIM model based risk assessment (focusing on beam object).

\begin{tabular}{|c|c|c|c|c|c|}
\hline Object Name & Location & Process & Hazard & Severity(S) & $\begin{array}{l}\text { Frequency } \\
\text { (F) }\end{array}$ \\
\hline \multirow{2}{*}{$\begin{array}{l}\text { Reinforcement } \\
\text { concrete_Rectangular Beam } \\
600 \times 400 \mathrm{~mm}\end{array}$} & \multirow[b]{2}{*}{$1^{\text {st }}$ storey } & Reinforcement assembly & Drop hand tool & 3 & 3 \\
\hline & & Carry reinforcing bar & $\begin{array}{c}\text { Drop reinforcing } \\
\text { bar }\end{array}$ & 4 & 3 \\
\hline \multirow{6}{*}{$\begin{array}{l}\text { Reinforcement } \\
\text { concrete_Rectangular Beam } \\
600 \times 400 \mathrm{~mm}\end{array}$} & \multirow{6}{*}{$2^{\text {nd }}$ storey } & Concrete placing & Collision & 3 & 3 \\
\hline & & Reinforcement assembly & Worker fall & 4 & 3 \\
\hline & & Reinforcement assembly & Drop hand tool & 3 & 3 \\
\hline & & Carry reinforcing bar & $\begin{array}{c}\text { Drop reinforcing } \\
\text { bar }\end{array}$ & 4 & 3 \\
\hline & & Formwork & Worker fall & 4 & 3 \\
\hline & & Concrete placing & Collision & 3 & 3 \\
\hline \multirow{3}{*}{$\begin{array}{c}\text { Reinforcement } \\
\text { concrete_Rectangular Beam } \\
600 \times 400 \mathrm{~mm}\end{array}$} & \multirow{3}{*}{$3^{\text {rd }}$ storey } & Reinforcement assembly & Worker fall & 4 & 3 \\
\hline & & Reinforcement assembly & Drop hand tool & 3 & 3 \\
\hline & & $\ldots$ & $\ldots$ & $\ldots$ & $\ldots$ \\
\hline
\end{tabular}

As a result of evaluating the beam objects scattered in the BIM model, it has a very large amount compared to the existing risk assessment results, and has duplicated items because it has the same construction and similar information. Figure 5 shows the risk level by removing duplicate items. The results of risk assessment for each type of work were derived, and the severity and frequency coefficients for each hazard were calculated. In other words, by classifying hazards for each process, risk assessments based on BIM were implemented by classifying the hazards that could occur at the construction site and providing the risk level accordingly. In the future, through additional research, it is necessary to reflect the reduction measures and build an evaluation report template accordingly to reach a level applicable to the business administration. 


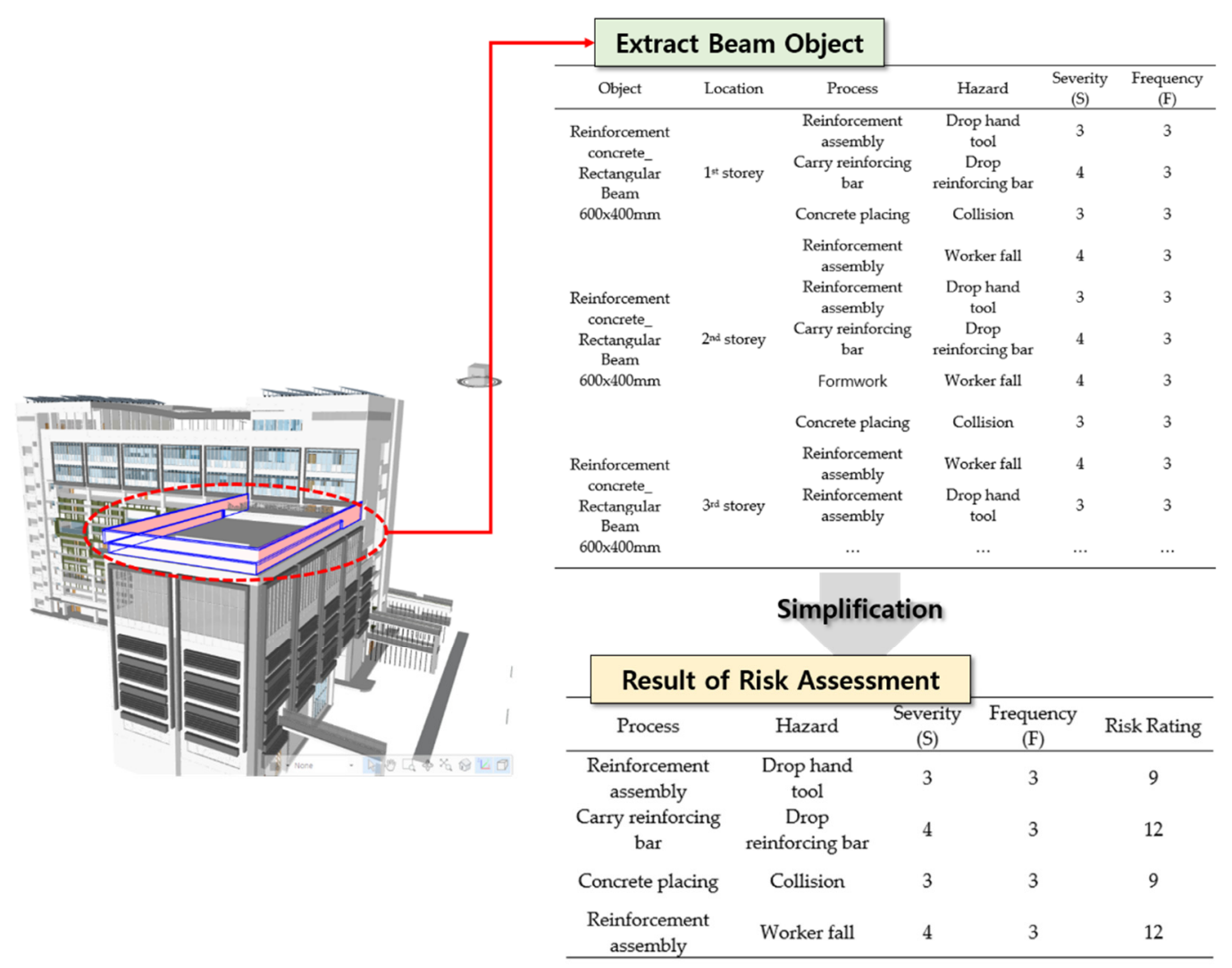

Figure 5. Simplification of hazard items for BIM-based risk assessment.

\section{Conclusion}

To respond to safety accidents at construction sites that have a high probability of such incidents, the government should identify and remove the causes of accidents during the design-construction phase in advance, and clarify its review of Design for Safety in order to ensure worker safety. It is time to enact definitive laws and regulations on the subject of Design for Safety review and clarify the elements to be reviewed. However, there is a lack of qualified experts for Design for Safety review work, which makes it difficult to apply in the field, and research on Design for Safety is insufficient. Therefore, this study is a part of an effort to achieve more accurate and reliable safety evaluations based on BIM. This study introduces a BIM-based construction safety management system by validating and applying a BIM-based risk assessment methodology.

First, this study was conducted based on literature data, so the information on the actual site is overwhelmingly insufficient. Currently, the information provided by the Ministry of Land, Infrastructure and Transport construction safety information system is provided mainly for serious disasters in large-scale construction sites. Due to the lack of information on disasters of small/middle-scale construction sites, there is a great difficulty in conducting risk assessment for disasters that occur frequently in actual construction sites.

Second, there is a lack of clear criteria for the calculation of safety risk ratings in Korea. Different interpretations exist for the same type of disaster, making it difficult for practitioners to quickly apply safety management principles at a given construction site. In KOSHA's design safety review task manual, there is no specific indicator of safety management at the level of work process, contents, and task scope. The KOSHA guidelines are also too fragmented to be widely distributed, making it difficult to apply them directly in the field.

Third, BIM information is limited by its 3D scope, which constrains risk assessments for potential disasters that need scenario-based evaluation. In other words, a separate BIM tool must be used to present all the available information about disaster scenarios, besides the 3D elements, so additional 
work is required. More accurate and objective evaluation elements should be collected from actual construction sites rather than mere literature reviews.

Finally, in order to overcome the technical limitations of current BIM-based modeling, automated evaluation technology should be developed. In the advent of the fourth Industrial Age, this can be accomplished by improving the quality of the available construction information and expanding the scope of evaluation technology based on artificial intelligence (AI) technologies.

The BIM-based risk assessment method suggested in this study can be used in both the design and construction stages. More risk assessment elements and the mathematical supplementation of risk assessment methods will be achieved through follow-up research on system development.

Author Contributions: Conceptualization, I.K.; Data curation, Y.L. and J.C.; Formal analysis, I.K., Y.L. and J.C.; Funding acquisition, I.K. and J.C.; Investigation, Y.L. and J.C.; Methodology, I.K., Y.L. and J.C.; Project administration, I.K.; Resources, I.K., Y.L. and J.C.; Supervision, I.K.; Validation, I.K., Y.L. and J.C.; Visualization, Y.L. and J.C.; Writing - original draft, I.K. and Y.L.; Writing - review \& editing, J.C. All authors have read and agreed to the published version of the manuscript.

Funding: This research was supported by a grant (20AUDP-B127891-04) from the Architecture \& Urban Development Research Program funded by the Ministry of Land, Infrastructure and Transport of the Korean government. This work was supported by the National Research Foundation of Korea (NRF) grant funded by the Korea government (MSIT) (No. NRF-2019R1F1A1062851).

Conflicts of Interest: The authors declare no conflict of interest.

\section{References}

1. Park, T. Occurrence of Industrial Accidents at the End of September. 2018. Available online: http: //www.kosha.or.kr (accessed on 24 September 2019).

2. Ministry of Employment and Labor. 2017 Industrial Accident Status Analysis Focusing on business accidents under the Industrial Accident Compensation Act; Ministry of Employment and Labor: Sejong-si, Korea, 2017.

3. Zhang, S.; Teizer, J.; Lee, J.-K.; Eastman, C.M.; Venugopal, M. Building Information Modeling (BIM) and Safety: Automatic Safety Checking of Construction Models and Schedules. Autom. Constr. 2013, 29, $183-195$. [CrossRef]

4. Zhang, S.; Sulankivi, K.; Kiviniemi, M.; Romo, I.; Eastman, C.M.; Teizer, J. BIM-based fall hazard identification and prevention in construction safety planning. Saf. Sci. 2015, 72, 31-45. [CrossRef]

5. Kim, K.; Cho, Y.; Zhang, S. Intergrating work sequences and temporary structures into safety planning: Automated scaffolding-related safety hazard identification and prevention in BIM. Autom. Constr. 2016, 70, 128-142. [CrossRef]

6. Gambatese, J.; Behm, M.; Hinze, J.W. Viability of Designing for Construction Worker Safety. J. Constr. Eng. Manag. 2005, 131, 1029-1036. [CrossRef]

7. Robert, B.R.; Joseph, A.D. Process Safety Management Guidelines for Compliance; OSHA: Washington, DC, USA, 1994; p. 3133.

8. Dewlaney, K.S.; Hallowell, M.; Fortunato, B.R. Safety Risk Quantification for High Performance Sustainable Building Construction. J. Constr. Eng. Manag. 2012, 138, 964-971. [CrossRef]

9. Howard, J. The State of the National Initiative on Prevention through Design; DHHS(NIOSH): Washington, DC, USA, 2014; pp. 2014-2123.

10. Fabrizio, B.; Orazio, C. A Methodology for Determining the Profitability Index of Real Estate Initiatives Involving Public-Private Partnerships. A Case Study: The Integrated Intervention Programs in Rome. Sustainability 2019, 11, 1371.

11. Ministry of Land, Infrastructure and Transport. Design for Safety Task Manual; Ministry of land, Infrastructure and Transport: Sejong-si, Korea, 2017.

12. National Law Information Center. Enforcement Decree of The Construction Technology Promotion Act 75-2. Available online: www.law.go.kr (accessed on 26 April 2019).

13. Building Construction Authority. Code of Practice on Buildability 2015 Edition; Building Construction Authority: Singapore, 2015.

14. WSH Council. Guidelines on Design for Safety; WSH Council: Singapore, 2008.

15. WSH Council. Workplace Safety and Health Guidelines Design for Safety; WSH Council: Singapore, 2016. 
16. Ministry of Manpower. A Guide to the Construction Safety Audit Scoring System; Ministry of Manpower: Singapore, 2013.

17. Health and Safety Executive. Construction (Design and Management) Regulation 2015; Guidance on Regulations; HSE: London, UK, 2015.

18. Williams, S. The Absolutely Essential Health and Safety Toolkit for the Smaller Construction Contractor; INDG344(rev2); HSE: London, UK, 2008.

19. Dewlaney, K.S.; Hallowell, M.R. Prevention through design and construction safety management strategies for high performance sustainable building construction. Constr. Manag. Econ. 2012, 30, 165-177. [CrossRef]

20. Rajendran, S. Sustainable Construction Safety and Health (SCSH) Rating System(ver.1); Oregon State University: Corvallis, OR, USA, 2006.

21. Dharmapalan, V. Risk Factor Quantification of Design Elements for Multistory Commercial Office Buildings; Oregon State University: Corvallis, OR, USA, 2012.

22. Development Bureau. Guidance Notes of Design for Safety; Development Bureau: Hongkong, 2013.

23. Development Bureau. Worked Examples of Design for Safety; Development Bureau: Hongkong, 2013.

24. Kim, J.W.; Kim, J.J. Disaster Risk Assessment by Work Unit of Construction Work for Improve the Efficiency of Design for Safety Task. J. Archit. Inst. Korea Struct. Constr. 2018, 34, 45-53.

25. Ji, K.H.; Choi, B.J. A Study on safety improvement of Underground wall construction to Design for Safety. Korea Acad. Ind. Coop. Soc. 2019, 20, 56-68.

26. Ministry of Land, Infrastructure and Transport, Construction Safety Management Information System(COMIS). Available online: https://www.cosmis.or.kr (accessed on 2 January 2020).

27. IFC 2x3 Edition Technical Corrigendum 1, BuildingSMART. Available online: http://www.buildingsmarttech.org/ifc/IFC2x3/TC1/html/index.htm (accessed on 4 March 2020).

28. Park, G. Let's Halve the Fall Disaster; Korea Occupational Safety \& Health Agency: Seoul, Korea, 2008.

29. Oh, B. Risk Assessment; Korea Occupational Safety \& Health Agency: Seoul, Korea, 2005.

(C) 2020 by the authors. Licensee MDPI, Basel, Switzerland. This article is an open access article distributed under the terms and conditions of the Creative Commons Attribution (CC BY) license (http://creativecommons.org/licenses/by/4.0/). 